\title{
Tecnofobia e ficção científica brasileira: o Complexo de Frankenstein no conto Ascensão e queda de Robhéa, manequim \& robô de Caio Fernando Abreu
}

\section{Tecnophobia and Brazilian science fiction: the Frankenstein Complex in the tale "Ascensão e queda de Robbéa, manequim e robô" by Caio Fernando Abreu}

\author{
Naiara Sales Araújo Santos* \\ Universidade Federal do Maranhão \\ São Luiz, Maranhã, Brasil \\ Jucélia de Oliveira Martins** \\ Universidade Federal do Maranhão \\ São Luiz, Maranhã, Brasil
}

\begin{abstract}
Resumo: O presente estudo tem como objetivo analisar o conto "Ascensão e queda de Robhéa, manequim e robô", do autor Caio Fernando Abreu e apontar aspectos que conferem a esta narrativa um cunho tecnofóbico. A tecnofobia na obra apresenta-se por meio do Complexo de Frankenstein, que é o medo direcionado aos seres artificiais produtos dos avanços tecnológicos. Para tanto, serão utilizados apontamentos de estudiosos tais como Alberto Cupani (2017), Isaac Asimov (1984), Langdon Winner (1986), Maria-Elena Osiceanu (2015), Zygmunt Bauman (2008), dentre outros.
\end{abstract}

Palavras-Chave: Ficção Científica. Tecnofobia. Complexo de Frankenstein.

\begin{abstract}
This study aims to analyze the tale "Ascensão e queda de Robhéa, manequim e robô" by the writer Caio Fernando Abreu and identify aspects that provide a technophobic nature to this narrative. The technophobia in this work is presented through the Frankenstein Complex, which is the fear toward artificial beings that are products of technological advances. For this, the productions of scholars such as Alberto Cupani (2017), Isaac Asimov (1984), Langdon Winner (1986), Maria-Elena Osiceanu (2015), Zygmunt Bauman (2008), among others will be part of the theoretical basis.
\end{abstract}

Keywords: Science Fiction. Technophobia. Frankenstein Complex.

\footnotetext{
* Doutora em Literatura Comparada. Professora do Programa de Pós-graduação em Letras da Universidade Federal do Maranhão (UFMA). Coordenadora do Grupo de Pesquisa FICÇA - Ficção Científica, Gêneros Pósmodernos e Representações Artísticas na Era Digital (UFMA). E-mail: naiara.sas2@gmail.com.

** Mestranda pelo Programa de Pós-graduação em Letras da Universidade Federal do Maranhão (UFMA - São Luis, Maranhão, Brasil), Pesquisadora bolsista da Fundação de Amparo à Pesquisa e ao Desenvolvimento Científico e Tecnológico do Maranhão (FAPEMA) e Membro do Grupo de Pesquisa FICÇA - Ficção Científica, Gêneros Pós-modernos e Representações Artísticas na Era Digital (UFMA). E-mail: jucelia.o.martins@gmail.com.
} 


\section{INTRODUÇÃO}

A tecnologia está em constante evolução, todos os dias surgem inovações que conferem agilidade e praticidade às nossas vidas. Porém há também um outro lado da tecnologia, aquele em que toda ação gera uma consequência. Os benefícios vem acompanhados de malefícios, mas as benesses são tão compensatórias que preferimos assumir os riscos. Isso, contudo, não impede o homem de ser cauteloso e conservar o temor de que as máquinas um dia alcançarão um nível superior de desenvolvimento e independência, que ele perderá a soberania que detêm sobre suas criações, fazendo com que estas se voltem contra seus criadores, substituindo-os. Este temor o escritor de ficção científica Isaac Asimov (1984) denominou como Complexo de Frankenstein.

Para Asimov, o Complexo de Frankenstein, que é o medo direcionado aos seres artificiais produtos da tecnologia, não possui um fundamento real que o justifique visto que na realidade os robôs são aliados da humanidade, protegendo o homem inclusive de sua própria natureza destrutiva. O referido autor criou as três leis da robótica $^{1}$, que regem o comportamento e ações dos robôs, justamente para desacreditar a possibilidade da incidência deste complexo. Todavia, o que é constantemente representado na literatura e outras artes, como o cinema, são máquinas cada vez mais humanizadas. Quanto mais os robôs adquirem características humanas, é alimentada também por parte da mídia a crença de que estes podem suplantar o homem, pois junto com as características físicas e comportamentais é levantada a hipotese de que eles também podem imitar os vícios de caráter.

Com o constante desenvolvimento tecnológico e suas consequências nem sempre positivas, ao longo dos anos, a literatura e outras artes acharam no embate Homem X Máquina uma fonte temática rentável e inesgotável para explorar. Na literatura brasileira é possível se verificar traços de uma tecnofobia característica do Complexo de Frankenstein em diversar obras, como a que será objeto de análise.

O presente estudo irá investigar a presença deste complexo no conto “Ascensão e queda de robhéa, manequim e robô" (1975), do escritor gaúcho Caio Fernando Abreu. Esse conto dividido em três partes, que ocorrem em momentos históricos diferentes, narra o desenrolar de uma epidemia que ocasiona na contaminação e progressiva destruição dos robôs, evento este que é denominado como a peste tecnológica. E ainda, descreve o destino da única sobrevivente deste evento, uma robô nomeada como Robhéa, e sua convivência forçada com humanos que dizimaram a sua espécie.

\footnotetext{
${ }^{1}$ Primeira Lei: Um robô não pode ferir um ser humano ou, por omissão, permitir que um ser humano sofra algum mal. Segunda Lei: Um robô deve obedecer às ordens que lhe sejam dadas por seres humanos, exceto nos casos em que tais ordens entrem em conflito com a Primeira Lei. Terceira Lei: Um robô deve proteger sua própria existência, desde que tal proteção não entre em conflito com a Primeira e/ou a Segunda Lei. (ASIMOV, 2009, p.9).
} 


\section{A TECNOLOGIA E SEUS ARTEFATOS}

O professor argentino Alberto Cupani (2017), no seu livro Filosofia da tecnologia: um convite, discorre que a tecnologia é um objeto de reflexão. Sua presença é tão inerente ao nosso cotidiano no mundo contemporâneo, que é impossível não pensar sobre ela, seja para expressar otimismo em relação às possibilidades fomentadas e/ou interesse em relação às melhorias que implementa em todos os setores das nossas vidas; seja para questionar limites ou temer consequências.

Para Cupani, a tecnologia demonstra ser uma realidade polifacetada. Ela não se apresenta "apenas em forma de objetos e conjuntos de objetos, mas também como sistemas, como processos, como modos de proceder, como certa mentalidade." (2017, p. 12). Logo, filosofar sobre a tecnologia não se limitaria ao questionamento sobre o que ela é e acerca das técnicas empregadas para fazer surgir os artefatos tecnológicos.

Ao agir, o ser humano está conduzindo sua própria existência, contudo ao fazer, ele está produzindo/fabricando um artefato, utilizando para isso técnica/arte. $\mathrm{O}$ artefato seria um objeto ou processo que é considerado artificial, justamente por causa da forma como se deu sua construção: “o artificial é aquilo que resulta da arte ou techné, distinguido do natural. " (CUPANI, 2017. p. 14)

Qualquer objeto fabricado pelo ser humano por meio do uso de técnica racionalmente fundamentada (técnica esta que na idade moderna passou a ser chamada de tecnologia, ao aliar o saber como 2 com o saber porquê 3), é um artefato tecnológico. A diferença entre a chamada técnica tradicional, que seria o uso do conhecimento de senso comum, adquirido por meio da vivência e observação, e a tecnologia, é que esta última vai além do conhecimento prático se utilizando da ciência aplicada, do fazer com racionalidade. Os artefatos tecnológicos são resultados da aplicação do saber teórico, da experimentação científica.

Segundo enfatiza Cupani (2017), a tecnologia (e consequentemente, os seus artefatos) não deve ser encarada como neutra: "No entanto, a máquina significou um diferente modo de vida, o que não foi percebido no início, de onde a ilusão de que a tecnologia constitua apenas um meio ou instrumento neutro, a serviço de quaisquer finalidades humanas." (CUPANI, 2017. p. 85)

Por isso, pode-se afirmar que filosofar sobre a tecnologia abrange ainda aspectos sociais e políticos derivados da sua utilização, como a análise dos impactos exercidos pela tecnologia sobre a sociedade e, até mesmo, a forma como ela se vincula ao exercício do poder.

Em um artigo denominado "Artefatos têm políticas?" do cientista político Langdon Winner (1986), discorre-se sobre a relação tecnologia e poder. No primeiro momento, as concepções de política e tecnologia são apresentadas:

Pelo termo "política" eu quero significar arranjos de poder e autoridade nas associações humanas assim como as atividades que ocorrem dentro desses arranjos. [...] o termo

know-how - Saber como fazer algo utilizando o conhecimento empírico.

know-why-Saber por que algo foi realizado, utilizando o conhecimento científico. 
"tecnologia" significará todos os artifícios práticos modernos. (WINNER, 1986, p. 3 e 4)

Logo, o termo política se ligará à ideia do poder/autoridade que um indivíduo ou pequeno círculo de pessoas exerce sobre a sociedade, ou uma comunidade específica, utilizando como suporte para o eficaz exercício, a tecnologia (entendida como os artefatos tecnológicos). Winner (1986) deixa claro que a política existe para as pessoas, não para as coisas/artefatos, mas que a forma como certas tecnologias são utilizadas serve para atender interesses políticos de grupos específicos.

Um exemplo que ele utiliza é o do arquiteto e urbanista Robert Moses. Este, para evitar o acesso de pessoas pobres e negras (que eram o público majoritário que utilizava o transporte público americano) ao parque público Jones Beach, desenvolveu o projeto e construção de viadutos baixíssimos sobre as vias em Long Island - Nova York. Vale ressaltar que o parque supracitado foi projetado por Moses visando servir de local de lazer a um público composto por pessoas brancas pertencentes à elite social e classe média (cuja maior parte já possuíam automóveis). Com essa ação ele conseguiu o seu objetivo: impedir o acesso dos ônibus a certas regiões, assim como ao parque Jones Beach, limitando o acesso das minorias raciais e pessoas de baixa renda a esses locais.

No exemplo acima, a tecnologia desenvolvida para conceder fluidez às rodovias serviu ao propósito, mas também foi utilizada como ato político no qual o urbanista usou o poder da sua reputação e influência para levar adiante a sua imposição sobre quem era o público adequado para frequentar o parque por ele projetado. Conforme afirma o professor Langdon Winner (1986, p. 9): "Neste sentido, inovações tecnológicas são similares a atos legislativos ou ações políticas básicas que estabelecem uma estrutura de ordem pública que pode durar por muitas gerações. "Ao utilizar a tecnologia desta forma, o efeito, assim como um ato político, pode vir a ser tão duradouro que afetará tanto a sociedade atual como as futuras.

Ainda sobre o tema tecnologia e poder, é interessante analisar a suposição de que os artefatos surgiram da necessidade do homem de ter controle sobre todas as situações que envolvem a sua existência.

No fim das contas, todas elas se resumem na aspiração ao controle e à determinação da realidade. Parece que nada pode ser deixado entregue ao seu desenvolvimento ou a sua ocorrência espontânea. É que, como diz Winner (1977), “em um sentido fundamental, determinar coisas é aquilo de que trata a tecnologia". O mundo deve se converter em uma totalidade disponível, controlada. E "exercemos controle sobre os objetos quando os submetemos deliberadamente e com sucesso ao nosso poder e os usamos como meios para os nossos fins" (LACEY, 1998, p. 119). Por isso, não pode surpreender que o computador seja a tecnologia por excelência em nossa época. Ele é sinônimo de controle ou da expectativa de controle. (CUPANI, 2017. p. 190)

Por meio da leitura de Cupani (2017), constata-se que o homem se sentia impotente perante as forças da natureza, por isso começou a fazer artefatos que permitiam adquirir e manter o controle. Por exemplo, não era satisfatório para o ser 
humano meramente conservar acesso ao fogo, proveniente dos restos de queimadas naturais para superar a escuridão da noite, pois ele ainda se mantinha refém dos desígnios da natureza. Por esse motivo, desenvolveu um modo de criar seu próprio fogo (iniciando sua caminhada rumo à iluminação artificial), para em seguida encontrar formas de transportar esse fogo utilizando objetos. Com o passar do tempo, o homem foi aperfeiçoando os artefatos conforme a ciência forneceu conhecimento, e isso tornou possível o desenvolvimento de tecnologias que consequentemente resultaram na lâmpada a óleo, no lampião a gás e nas lâmpadas elétricas fluorescente, Led, a vapor ou naquelas movidas a energia eólica, solar ou de biomassa.

Com a evolução da ciência, o homem continuou a aperfeiçoar os artefatos utilizando tecnologias mais avançadas. Considerando a natureza como algo subjugado e que agora poderia ser manipulado conforme fosse conveniente, a humanidade passou a expandir a capacidade dos objetos tecnológicos utilizando-os como formas de melhorar a qualidade de vida e superar os limites que a própria constituição biológica tornava intransponíveis. Diferentes dos pássaros, os homens não nasceram aptos a voar pelos céus, todavia, a tecnologia permitiu a construção das naves espaciais, um artefato mais eficiente que as asas das aves pois permite chegar ao espaço e suas estrelas.

Acompanhando o progresso tecnológico, irrompem na sociedade as consequências, nem sempre positivas, mas consentidas em prol do progresso. A ambição pelo poder aliada ao orgulho excessivo e à necessidade exacerbada de manter tudo sob seu julgo, fez o ser humano ambicionar criar artefatos mais complexos, mesmo que sua criação envolva a quebra de alguns tabus ou prerrogativas sagradas, como a criação de vida, vida não natural, cuja gestação traz à luz um ser inorgânico, e, portanto, artificial.

É importante dizer que o objeto tecnológico por carregar a insígnia da artificialidade (devido ao seu processo criação), não tem que se sujeitar a nenhum limite imposto aos seres orgânicos (como a iminência da morte) podendo ser aperfeiçoado indefinidamente. Com o passar dos anos, a criatura se tornando mais perfeita, enquanto o criador segue estagnado devido as suas limitações, o homem inevitavelmente passa a refletir se sua criação não poderia um dia superá-lo, destruílo, ou pior, substituí-lo.

A seguir discorrermos sobre o fato do Complexo de Frankenstein possuir um viés tecnofóbico, entretanto, antes se faz necessário abordar a diferença entre tecnofobia e tecnofilia para situar em qual destes enfoques se enquadra esse complexo.

\section{TECNOFOBIA E O COMPLEXO DE FRANKENSTEIN}

Um marco histórico que demonstra a capacidade dos avanços tecnológicos na transformação social são as Revoluções Industriais. Isaac Asimov (1984), conforme relatado no primeiro capítulo, acreditava que somente com a primeira Revolução Industrial surgiu a verdadeira ficção científica, pois ela seria uma resposta literária às mudanças ocasionadas a partir de 1800. 
Naturalmente, ninguém seria capaz de adquirir essa noção enquanto a velocidade das mudanças científicas e tecnológicas não se tornasse suficientemente grande para ser observada pelas pessoas no decurso de suas vidas. Isso ocorreu com a Revolução Industrial, digamos, em torno de 1800. Só a partir de então pôde surgir a ficção científica. (ASIMOV, 1984, p. 118)

Para esse autor, era mister que os escritores tivessem noção do poder da ciência e da tecnologia na construção do futuro para conseguirem escrever com propriedade uma narrativa de cunho tão extrapolativo como a ficção científica. E, apesar do progresso tecnológico ter crescido de forma constante ao longo dos séculos, ressaltando que em cada área uma nova descoberta somente foi possível graças ao legado construído por sua predecessora, com a visível aceleração no ritmo das produções despontado pelas máquinas na primeira Revolução Industrial, os frutos da tecnologia além de experienciados passaram também a ser testemunhados pelos indivíduos.

Asimov (1984) não menospreza a importância da Revolução Científica (termo atribuído ao filósofo francês Alexandre Koyré) desencadeada entre 1550 a 1650, pois ela possibilitou a criação de uma fraternidade científica de abrangência continental ao separar ciência e religião, desmitificando a primeira. A Revolução Científica influenciou muitas obras de protoficção científica4, mas foi a Revolução Industrial que criou um ambiente propício ao florescimento da ficção científica nos moldes que se conhece hoje.

Na coletânea Automação \& Sociedade, Marcos T. J Barbosa, Marcos Baisso e Marcos T. Almeida, em um artigo denominado Surge uma nova sociedade, abordam a demarcação das Revoluções Industriais, enfatizando que não há unanimidade na comunidade acadêmica sobre o assunto, mas optam por apresentar a ideia de que elas são definidas por dois vetores: tecnologia e organização social.

Com base nesses dois vetores, a primeira revolução, iniciada em 1760 foi provocada pelo surgimento da máquina a vapor e pelo início do desenvolvimento do pensamento econômico liberal [...]. A segunda revolução se iniciou no início do século XX, impulsionada pela criação da linha de montagem e pela proposta de Frederick Winslow Taylor de utilização de métodos cartesianos na administração das empresas [...] A terceira revolução começou na década de 60 do século XX, com a robotização e a automação, tendo, do ponto de vista de organização social, suas bases estabelecidas na década anterior, com plano Marshall, que gerou o fluxo de investimentos que impulsionou a inovação nesta revolução [...]. A revolução que vivemos agora foi denominada por Schwab como a Quarta Revolução Industrial. Do ponto de vista tecnológico, é o da convergência das tecnologias dos mundos digital, físico e biológico [...]. (BARBOSA; BAISSO e ALMEIDA, 2018, p. 4)

Todas as Revoluções Industriais têm em comum avanços (ocasionados pela utilização de novas tecnologia) que contribuem de modo eficaz na celeridade de determinados procedimentos que, por sua vez, afetam diretamente atividades

4 Protoficção cientifica é a expressão utilizada por alguns observadores, consoante enfatiza o escritor Roberto de Sousa Causo (2003, p.51), para designar as obras que possuem aspectos característicos da narrativa de ficção científica, antes deste gênero receber uma nomenclatura. 
essenciais para o desenvolvimento econômico e geram significativas transformações na organização da sociedade.

A primeira Revolução Industrial ocasionou na mecanização de procedimentos (com o uso do carvão e do ferro), resultando em um massivo êxodo rural, enriquecimento da burguesia e condições de vida subumanas para o proletariado. A segunda é decorrente da melhoria dos meios de produção surgidos na primeira revolução e financiamento de pesquisas que ocasionaram na descoberta e utilização de novas fontes de energia, como a eletricidade e o petróleo. Os eventos mais marcantes deste período foram as Guerras Mundiais, no que pese a tecnologia serviu ao aprimoramento de artefatos para a indústria bélica.

A Revolução digital ou terceira Revolução Industrial caracteriza-se pela substituição da tecnologia analógica pela digital (em sua forma mais básica) e desenvolvimento nos campos da robótica industrial, biotecnologia e tecnologia espacial. Esta revolução ocasionou o desemprego estrutural, principalmente entre a parcela mais empobrecida da população sem acesso à inclusão digital.

Atualmente o mundo vive a quarta Revolução Industrial ou Indústria 4.0. Ela eleva a tecnologia digital a um novo patamar, revolucionando-a. Hoje o mundo físico é diretamente afetado pela ausência de barreiras no mundo virtual, o último tornouse um lugar onde dados e informações são processados e compartilhados em tempo real, sendo possível a interconectividade entre pessoas, setores industriais e países. Existe também uma preocupação em aliar o desenvolvimento sustentável com o progresso tecnológico. Outro fator que merece consideração é a proliferação de transtornos psicológicos advindos do uso intenso de tecnologias digitais, como Nomophobia5 ou Cybersickness6.

Conforme observou-se, em todas as revoluções houve grandes avanços tecnológicos, entretanto, agregados aos benefícios desencadearam-se sequelas preocupantes. Conforme Asimov (1984): “A ficção científica é o ramo da literatura que trata das respostas do homem às mudanças ocorridas ao nível da ciência e da tecnologia" (ASIMOV, 1984, p. 20). Por essa razão, esta sempre busca prognosticar aos seus leitores às prováveis mudanças sociais que decorrem da utilização das inovações tecnológicas e como estas são recepcionadas com otimismo ou pessimismo:

Consequentemente, ao passo que algumas pessoas permaneciam na expectativa de que o avanço da ciência e tecnologia seria um meio capaz de permitir o advento da Utopia na face da Terra, outras temiam os resultados das mudanças e anteviam o surgimento de pesadelos. Assim, desde os seus primeiros tempos, a ficção científica oscilou entre dois pólos: o do otimismo e o do pessimismo. (ASIMOV, 1984, p. 125)

Consoante, atendam ou não suas expectativas, a tecnologia pode ser encarada com euforia ou tranquilidade: por aqueles que enxergam nela possibilidades de

\footnotetext{
É uma forma de crise de ansiedade, ou até mesmo um medo implausível, decorrente da impossibilidade de acesso a um aparelho smartphone (celular que possui sistema operacional, assim como um computador), seja por estar sem bateria ou em um local sem sinal.

6 Também conhecida como Náusea digital, acontece quando o usuário, ao acessar o meio virtual, sente ânsia de vômito, vertigem ou mesmo desorientação, tendo em vista que o cérebro reconhece a movimentação existente nestas plataformas como sendo real.
} 
ascensão social ou melhoria na qualidade de vida, aflorando o sentimento tecnofilia. E ainda, com desconfiança ou temor: pelos indivíduos que não tiveram acesso à formação científica (desconhecendo o efeito de certas tecnologias); ou por aqueles que entendem o desenvolvimento e uso de certos artefatos tecnológicos como maléficos para o bem-estar da sociedade, qualquer que seja o benefício gerado, o que não compensaria os riscos. Seja desconhecimento ou precaução, ambos resultariam em atitude tecnofóbica em relação a estes artefatos.

A professora e psicóloga romena Maria-Elena Osiceanu (2015) conceitua tecnofilia e tecnofobia das seguintes formas:

A tecnofilia é definida como a atração, o entusiasmo de um indivíduo humano pelas atividades que envolvem o uso de tecnologias avançadas. É expressa pela facilidade de adaptação às mudanças sociais provocadas pelas inovações tecnológicas. O termo tecnofilia é usado para destacar como a tecnologia pode evocar fortes sentimentos positivos sobre o futuro.

$[\ldots]$

A tecnofobia é definida como um medo irracional ou ansiedade causada pelos efeitos colaterais das tecnologias avançadas. A definição envolve dois componentes: primeiro, o medo dos efeitos colaterais do desenvolvimento tecnológico na sociedade e no meio ambiente; e segundo, o medo de usar dispositivos tecnológicos como computadores e tecnologia avançada. (OSICEANU, 2015, p.1138 e 1139, tradução nossa) ${ }^{7}$

Segundo observa a autora supracitada, o termo tecnofília vem do grego $\tau \dot{\varepsilon} \chi \nu \eta$

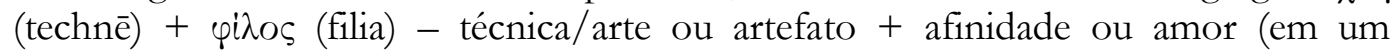
sentido fraterno/ de amigo, não no romântico), sendo utilizado para se referir ao sentimento de entusiasmo sentido diante do uso de novas tecnologias. O sujeito tecnofílico não teme o desenvolvimento dos artefatos tecnológicos (que avançam mais a cada dia) e seus efeitos para o futuro, mas sim os recebe com satisfação e a certeza de que estes serão benéficos para a humanidade, pois podem servir na resolução de diversos problemas sociais que os homens não resolveriam sem eles. A tecnofilia, na sociedade contemporânea, é vista como fenômeno normal, a adaptação às novas tecnologias vem transcorrendo de forma natural. Somente quando esse "amor pelo tecnológico" torna-se excessivo, adquire o status de patológico.

Um exemplo seria o vício em internet (ou Transtorno de dependência à internet). O usuário começa utilizando a internet pelas mais diversas razões (trabalho, estudo, entretenimento...) e com o passar do tempo aquela atividade proporciona satisfação e prazer, o que ocasiona relação tecnofílica com essa tecnologia. Porém, quanto mais a pessoa se desliga e ignora as responsabilidades e relações interpessoais do mundo real para se dedicar ao mundo virtual, aquele vínculo passa a ser abusivo e

Technophilia is defined as attraction, enthusiasm of the human individual determinated by the activities which involve the use of advanced technologies. It is expressed by easily adaptation to the social changes brought by technological innovations. The term of technophilia is used to highlight how technology can evoke strong futuristic positive feelings. [...] Technophobia is defined as an irrational fear or anxiety caused by side effects of advanced technologies. Definition involves two components: first the fear for side effects of technological development on society and the environment; and second, the fear of using technological devices such as computers and advanced technology. 
obsessivo. E assim como tudo que é excessivo, esse tipo de conduta prejudica a saúde física e mental do usuário, conferindo-lhe efeitos semelhantes ao de um dependente químico. Logo, a vivência com o artefato tecnológico da internet deixa de ser apenas tecnofília, sendo também patologia.

Em contrapartida, a expressão tecnofobia vem da junção das palavras gregas $\tau \dot{\varepsilon} \chi \nu \eta($ technē) $+\varphi \dot{\beta} \beta o \varsigma$ (fobia) - técnica/arte ou artefato + medo, e designa o medo, desgosto ou mesmo a sensação de desconforto que um indivíduo sente ao utilizar tecnologias modernas ou artefatos tecnológicos. Enfatizando que estes sentimentos não impedem o contato da pessoa com o artefato que causa aversão, podendo ser até mesmo a inevitabilidade de seu uso (para evitar a sensação de estar à margem) que intensifique a rejeição. Inclusive, haveria grau de tecnofobia: desde a forma mais leve (que seria leve ansiedade por não entender bem como utilizar determinada tecnologia) até a mais intensa (podendo esse temor apresentar sinais físicos, como mãos suadas, batimentos cardíacos acelerados, etc.).

O sociólogo polonês Zygmunt Bauman (2008), na obra Medo líquido, define que: "Medo é o nome que damos a nossa incerteza: nossa ignorância da ameaça e do que deve ser feito - do que pode e do que não pode - para fazê-la parar ou enfrentála, se cessá-la estiver além do nosso alcance." (BAUMAN, 2008, p. 8). Para esse autor, o medo seria também uma sensação de insegurança gerada pelo sentimento de impotência diante da perda de um controle que escapou ou foi tirado de nossas mãos.

Conforme o autor Yi-fu Tuan (2005), o medo constitui um sentimento complexo, pois engloba o sinal de alerta diante de um evento inesperado e a sensação de ansiedade: "A ansiedade é um pressentimento de perigo quando nada existe nas proximidades que justifique o medo. A necessidade de agir é refreada pela ausência de qualquer ameaça." (TUAN, 2005, p. 10)

O medo voltado para a tecnologia e seus artefatos é retratado constantemente na ficção científica:

Esse tratamento de ficção científica contribuiu para exacerbar uma variedade especial de tecnofobia: o medo do progresso tecnológico em relação aos robôs como "sacrílego", e o consequente receio de tudo o que for autômato, que supera e ultrapassa o de todos os outros produtos da tecnologia. E por isso que em minhas histórias qualifico esse medo de "complexo de Frankenstein". (ASIMOV, 2007, p.12)

Asimov (2007) apresenta o Complexo de Frankenstein como uma variedade especial de tecnofobia, cujos agentes do mau seriam os seres dotados de vida artificial (como os robôs). Maria-Elena Osiceanu (2015) também aponta esse medo ou ansiedade voltados para o tecnológico, como sendo injustificável e exagerado. Pensamento corroborado por Asimov (2007), que aponta o Complexo de Frankenstein como temor irracional e por antecipação, sem justificativa plausível.

A seguir pretende-se perscrutar como o medo voltado ao artefato tecnológico robô, que o escritor Isaac Asimov (2007) denominou Complexo de Frankenstein, se faz presente na obra Ascensão e queda de Robhéa, manequim e robô. 


\section{ASCENSÃO E QUEDA DE ROBHÉA, MANEQUIM \& ROBÔ - CAIO FERNANDO ABREU (1975)}

Ascensão e queda de Robhéa, manequim e robô, escrito entre os anos de 1969 e 1973 pelo escritor Caio Fernando Abreu, foi publicado com outros contos em uma coletânea intitulada $\mathrm{O}$ ovo apunhalado em 1975.

O conto supramencionado é dividido em três partes, que ocorrem em momentos históricos diferentes. A primeira parte se inicia com uma epidemia que ocasiona na contaminação e progressiva destruição dos robôs, evento que futuramente seria denominado como a peste tecnológica.

No sétimo dia morriam pelas esquinas em estilhaços metálicos e ruídos de ferragens. A epidemia se alastrara de tal modo que se tornara muito fácil surpreendê-los. Os policiais nem mais se preocupavam em armar ciladas, disfarçando-se de civis para poderem acompanhar e prevenir a evolução da peste.

$[\ldots]$

Findo esse prazo, tombavam pelas praças e ruas, os olhos de vidro explodindo em pedacinhos coloridos, as engrenagens enferrujadas não obedecendo às ordens dos cérebros enfraquecidos. (ABREU, 2018, p. 44)

O governo, chamado no conto de Poder, começa a adotar medidas repressivas contra os contaminados (na narrativa a peste tecnológica somente atinge os seres artificiais), minando assim qualquer chance que estes eventualmente teriam de sobreviver. Se os robôs se utilizavam de estimulantes para manter o cérebro ativo, evitando a deterioração dos membros compostos de engrenagens enferrujadas, o Poder retirava das farmácias os estoques de estimulantes; procuravam-se oficinas mecânicas para substituir peças, o Poder ordenava o fechamento de todas elas.

Já neste início de narrativa é possível constatar a influência de uma tecnofobia voltada contra os robôs (ou Complexo de Frankenstein), pois nesta sociedade construída por Caio Fernando Abreu os seres artificiais são tratados como o "outro", um ser que não faz parte, e, portanto, indesejado e indigno de confiança. Por essa razão, diante da oportunidade de ceifar-lhes a existência o Poder utiliza de todos os artificios para atingir tal fim, seja por meio de ciladas ou da omissão de socorro.

As medidas realizadas pelo Poder somente conseguem ser bem-sucedidas haja vista que foram legitimadas pela população normal (ou humana), devido ao fato desta já ter internalizado o Complexo de Frankenstein, levando em conta que os robôs neste contexto eram os inimigos que eventualmente iriam suplantá-los. Segundo Asimov (2007) a sociedade tende a imputar as máquinas a transferência de culpa pelos mais diversos males sociais, como o desemprego sistêmico:

Não perceberam que o inimigo era uma sociedade que pouco se importava com "classes inferiores" e não sentia a mínima responsabilidade pelos pobres. Da maneira mais simplista, atribuíram a culpa de sua desgraça às máquinas. Por isso, durante as manifestações, destruíram ou procuraram danificar as máquinas que, em sua opinião, os tinham substituído. (ASIMOV, 2007, p.9) 
O cenário construído no conto é de profunda crise econômica, motivo pelo qual não é irracional se supor que os robôs na realidade foram utilizados como bodes expiatórios8 pelo Poder, que utilizando a sua influência aproveitou-se de uma epidemia (que possivelmente poderia ter sido resolvida, com o cuidado adequado) para propagar discursos de ódio e aumentar o grau de tecnofobia contra os robôs presentes na narrativa: "Motivo bem mais justo para a tecnofobia e que conta com o maior número de simpatizantes é o medo de que o progresso tecnológico tire o emprego de muita gente". (ASIMOV, 2007, p.9)

Foi a utilização de toda sorte de medidas repressivas que obrigou os robôs a fugirem:

Legiões fugiam em direção ao campo, corriam boatos de que era a proximidade com as máquinas o que provocava as mutações. Mas sabendo também da possibilidade de se formarem grandes comunidades rurais, o Poder fechou todas as saídas das cidades.

Então eles morriam feito ratos, sem que fosse necessário sequer procurá-los. Seus pedaços eram recolhidos tediosamente pelos caminhões de limpeza e encaminhados aos ferros-velhos, onde seriam vendidos como sucata. (ABREU, 2018, p. 45)

No trecho acima fica evidenciada a presença do Complexo de Frankenstein, como um temor por antecipação (sem uma justificativa plausível que a ratifique) que a população normal já nutria pelas máquinas, e que os faz acreditar nos boatos e não averiguar os fatos. As pessoas preferem se precaver diante de uma possibilidade, mesmo o custo sendo a dizimação de toda uma espécie.

Com o fechamento da entrada da cidade, os robôs acurralados e sem qualquer tipo de assistência por parte do governo e da população normal (ou humana) começam a morrer, sendo seus corpos dilacerados e espalhados pelas ruas. Por essa razão, o Poder realiza uma política de incentivo ao uso dos restos dos contaminados, fomentando assim o crescimento econômico (pois as sucatas foram utilizadas pelos setores da indústria e comércio) superando-se a crise e aumentando a empregabilidade para a população humana:

Esperava-se também que, em breve, a epidemia fosse completamente esquecida pela faixa dita normal da população, e futuramente braços e pernas e seios e pescoços pudessem ser utilizados como objetos decorativos. Esperava-se ainda industrializar estilhaços de olhos para transformá-los em contas coloridas que seriam utilizadas na confecção de colares cheios de axé, para serem vendidos a turistas ávidos de exotismo. (ABREU, 2018, p. 45)

Tal estímulo aumentou o prestígio e a influência que o Poder tinha sobre os normais, que passou a considerá-lo como um governo que adotava medidas eficientes e criativas com a finalidade de superar a crise. Segundo a professora americana Mary Elizabeth Ginway (2005) é característico da Ficção Científica retratar as máquinas de uma maneira mais negativa em cenários de crise :

8 Bode expiatório é uma expressão utilizada para designar aquele que recebe a culpa (e por vezes também a punição) pelas consequências de um evento a qual não deu causa. 
[...] durante qualquer período de tempo, a ficção científica é influenciada por atitudes populares com respeito à tecnologia e às máquinas, de modo que durante épocas de declínio econômico e desemprego, as máquinas são geralmente percebidas como uma ameaça ao tecido social. (GINWAY, 2005, p. 172

E como foi a utilização dos restos imortais dos robôs que fomentou o crescimento econômico (revertendo a crise), a tecnofobia superou a tecnofília, motivo pelo qual há uma atitude de permissividade da população diante das medidas contra os robôs praticadas pelo Poder.

$\mathrm{Na}$ segunda parte do conto, a peste tecnológica se tornou acontecimento superado, que habitava no passado. Contudo, um jornalista resolve reviver o assunto ao questionar os motivos que culminaram na peste que resultou na destruição em massa dos robôs. As indagações feitas pelo jornalista são primeiramente encaradas com hostilidade pela sociedade, todavia suscitam o despertar da curiosidade sobre aquele evento:

Talvez devido a esses boatos, ou mesmo porque o povo não havia realmente esquecido a Peste Tecnológica - como fora chamada para efeitos sociológicos - ou ainda porque algumas das hipóteses aventadas pelo jornalista, e que não vêm ao caso, fossem bastante viáveis, o fato é que uns quinze dias mais tarde o jornal dobrou sua tiragem e o assunto passou a ser comentado nos bares da moda. (ABREU, 2018, p. 46)

Mas essa curiosidade, diferentemente do que se imagina, não conduziu as pessoas a questionarem os motivos que ocasionaram a dizimação dos robôs e as razões por trás da total ausência de assistência por parte do Poder, mas sim a utilizarem esse evento para autopromoção e como forma para ganharem dinheiro.

Os costureiros lançaram a linha-robô, com roupas inteiramente de aço e maquiagem metálica, os oculistas criaram novas lentes de contato acrílicas, especialmente para dar aos olhos o efeito do vidro. Surgiram novos manequins, de movimentos endurecidos e olhos vidrados. Tornou-se extremamente chique freqüentar oficinas mecânicas em vez de saunas, academias de dança ou institutos de beleza.

$[\ldots]$

O Movimento Tecnológico - que a essa altura já influenciava seriamente a música, a literatura, as artes plásticas, a moda e demais formas de expressão - ultrapassou as limitadas fronteiras do país para atingir o mundo inteiro. $O$ índice de exportações aumentou incrivelmente, o país viu crescer suas divisas, artistas estrangeiros e turistas animados invadiam as cidades e as praias. E um tempo de prosperidade começava. (ABREU, 2018, p.46 a 48)

Conforme acima, há na segunda parte do conto forte crítica feita por Abreu (2018) à sociedade de consumo e seus valores supérfluos. Consoante leitura extraída de Cupani (2017) entende-se que os artefatos tecnológicos por serem estreitamente relacionados ao sistema capitalista de consumo não são acessíveis a todos, apenas a uma pequena parcela da população que tem poder aquisitivo suficiente para acompanhar as novas tendências tecnológicas, e que não se preocupa de fato com questões como a disparidade entre classes sociais. 
Por outra parte, a rápida associação com o capitalismo fez com que as inovações tecnológicas não pudessem ser adequadamente assimiladas pela sociedade: elas estiveram desde cedo a serviço do proveito particular e não do bem-estar geral (o que poderia ter sido evitado). (CUPANI, 2017. P. 76)

Neste momento do conto da narrativa também se apresenta o robô objetificado: um ser cuja vida artificial não significa nada (pois não possui uma alma). O robô é visualizado apenas uma matéria-prima a ser utilizada pela indústria ao seu bel-prazer, resultando em itens cujo único intuito é servir as demandas do mercado.

$\mathrm{Na}$ terceira e última parte do conto, é descoberto o fato de que alguns robôs sobreviveram à peste. Todavia, estes viviam em condições precárias e sem contato com a humanidade, enquanto aguardavam o momento de voltarem à superfície para tomar o poder. Mas eles foram descobertos, denunciados, encurralados por policiais e em seguida destruídos, com exceção de uma robô:

A rua suspeita foi cercada, os policiais derrubaram as portas com metralhadoras e encurralaram os contaminados contra uma parede úmida onde, com fortes jatos d'água, conseguiram enferrujar lentamente suas articulações. Morreram todos, da mesma maneira que seus precursores - à exceção de uma jovem inteiramente mecanizada, com grandes olhos em vidro rosa e magníficas pernas de aço. (ABREU, 2018, p.48)

É verdade que os robôs sobreviventes almejavam retornar a superfície para se vingarem dos seus criadores, que também foram os responsáveis direta ou indiretamente pela opressão que aqueles vivenciaram; todavia a realidade é que tal desejo era um sonho útopico, levando-se em conta a situação de precariedade extrema nas quais os robôs se encontravam. Por isso, pode-se afirmar que a atitude do Poder de dizimar os robôs restantes foi motivado pelo desejo de assegurar a manutenção do controle e de demonstrar a sua soberania, do que apenas um mero medo do tecnológico. Cupani (2017) esclarece que essa necessidade de controlar todos os aspectos que permeiam a sua existência é uma obsessão do ser humano:

Houve um esforço geral na direção de satisfazer as necessidades humanas aumentando a riqueza material. Por trás desse esforço estava um "impulso obsessivo" de conquistar a Natureza e controlar a vida. As ideias de ordem e de previsibilidade se apoderaram de todas as áreas da existência. (CUPANI, 2017. P. 89 e 90)

A robô sobrevivente seria aniquilada como seus companheiros, porém por possuir beleza exótica, chamou a atenção de um estilista renomado que utilizou sua influência e contatos para mantê-la em funcionamento, podendo fazer uso como sua principal manequim.

A robô então recebe uma nova identidade, o nome artístico de Robhéa, e torna-se enorme sucesso, sofrendo intenso assédio pelo público e pela mídia.

Galgou todos os degraus da fama em pouquíssimo tempo, acabando por filmar com os cineastas mais em voga no momento, ganhando prêmios e mais prêmios em festivais internacionais e sendo eleita Rainha das Atrizes durante cinco carnavais seguidos. Foi no último carnaval que, sem dar explicações, ela fugiu abruptamente do baile, espatifando a fantasia e repetindo em inglês que queria ficar sozinha. Retirou-se para uma ilha deserta e inacessível, onde viveu até o fim de seus dias. 
Muitos anos depois, os jornais publicaram uma pequena nota comunicando que Robhéa, ex-manequim, ex-atriz de cinema e robô de sucesso em passadas décadas, suicidara-se em sua ilha deserta e inacessível tomando um fatal banho de chuveiro. (ABREU, 2018, p.49)

Submetida à existência sem liberdade, tendo sua imagem e corpo explorados e constituindo a última de sua espécie, são fatores que conduzem a preferir o isolamento total e posteriormente o suicídio. Contudo, no fim do conto, nem mesmo a morte proporciona a ela autonomia sobre seu ser, pois seus restos enferrujados são mumificados para serem exibidos em praça pública.

Desde sua primeira aparição até o final do conto, Robhéa é tratada como um objeto cujo único propósito de vida é servir aos seus senhores seres humanos. Ginway (2005) afirma que na literatura brasileira o robô é majoritariamente apresentado no papel de servo, é um escravo moderno nascido de forma artificial: "A presença de robôs e de um novo tipo de escravatura demonstra que questões dolorosas de raça e classe ainda estão profundamente embutidas na consciência brasileira." (GINWAY, 2005, p. 177).

A robô Robhéa também apresenta similitudes com o monstro do livro Frankenstein ou o Prometeu Moderno, da escritora Mary Shelley. Segundo o crítico britânico Adams Roberts (2018):

Outro meio ainda de explicar seria encarar o Monstro como um poderoso símbolo de solidão existencial. Ninguém de fato vê nem ouve o Monstro - por certo não, como sugeri, as muitas pessoas que adaptaram sua história a outras mídias reduzindo-o ao silêncio. Apenas dão conta do que o Monstro faz e, mesmo assim, só quando ele age com violência. (ROBERTS, 2018, p. 196).

Assim como todos os robôs do conto, o monstro criado por Victor Frankenstein somente é ouvido quando se revolta e mesmo assim o que importa é a voz de quem o rodeia, dos personagens humanos. Tanto que mesmo famosa, rica e idolatrada por centenas de pessoas durante o auge da fama, a solidão de Robhéa é palpável, tanto que ela opta pelo suicídio.

\section{CONSIDERAÇÕES FINAIS}

Com base no exposto, é constatável a existência de uma tecnofobia voltada contra os robôs no conto Ascensão e queda de Robhéa, manequim e robô, do escritor gaúcho Caio Fernando Abreu. $\mathrm{Na}$ narrativa os seres artifíciais não realizam nenhuma ação que os tornem dignos de temor pelos seres humanos, sendo sua simples existência e constituição física que os tornam dignos de desconfiança.

$\mathrm{Na}$ literatura o termo Robot (robô) nasceu em 1920 na peça a $A$ fábrica de robôs, do tcheco Karel Tchápek. E nela a expressão já designava uma nova modalidade de servo: a de seres dotados de vida artificiais que foram criados para realizar trabalhos em regime de escravidão. E a literatura brasileira adotou essa significação, pois seus robôs possuem como único propósito de vida servirem seus senhores humanos. 
O Complexo de Frankenstein é um temor por antecipação de que os robôs se voltem contra os seus criadores, substituindo-os. E no conto, inicialmente não se verifica nenhuma intenção maléfica dos seres artificiais, e mesmo quando um traço desta surge sua possibilidade de sucesso é infíma. Verificou-se que a razão que motiva as ações repressivas do Poder e omissivas das pessoas contra os robôs não é somente a tecnofobia, mas sim a necessidade da espécie humana de ter controle sobre as situações e exercer pleno domínio sobre aqueles que ela considera inferiores.

\section{REFERÊNCIAS}

ABREU, Caio Fernando. O ovo apunhalado. Porto Alegre: L\&PM, 2018.

ASIMOV, Isaac. Eu, robô. Tradução de Jorge Luiz Calife. Rio de Janeiro: PocketOuro, 2009.

ASIMOV, Isaac. Histórias de robôs. Volume 1. Tradução de Milton Persson. Porto alegre: L\&PM Pocket, 2007.

ASIMOV, Isaac. No mundo da fiç̧ão científica. Tradução de Thomaz Newlands Neto. Rio de Janeiro: Francisco Alves: 1984.

BARBOSA, Marcos T. J.; BAISSO, Marcos; Almeida; Marcos T. Surge uma nova sociedade. In.: Silva, Elcio B.; et al. Automação e sociedade: quarta revolução industrial, um olhar para o Brasil. Rio de Janeiro: Brasport, 2018.

BAUMAN, Zygmunt. Medo líquido. Tradução: Carlos Alberto Medeiros. Rio de Janeiro: Zahar, 2008.

CUPANI, Alberto. Filosofia da tecnologia: um convite. 3. ed. Florianópolis: Editora UFSC, 2017.

MAGGIO, Elisabeth, et al. Sete faces da ficção científica. Organização de Márcia Kupstas. São Paulo: Moderna, 1992.

OSICEANU, Maria-Elena. Psychological implications of modern technologies: "technofobia" versus "technophilia", On-line, Procedia - Social and Behavioral Sciences 180, 2015, p. 1137 - 1144. Disponível em: https://cyberleninka.org/article/n/ 1211257/viewer. Acesso em: 20 maio 2019.

ROBERTS, Adams. A Verdadeira História da Ficção Científica: do Preconceito à Conquista das Massas.1. ed. São Paulo: Seoman, 2018.

TCHÁPEK, Karel. A fábrica de robôs. Tradução de Vera Machac. São Paulo: Hedra, 2010.

TUAN, Yi-fu. Paisagens do medo. Tradução Lívia de Oliveira. São Paulo: editora UNESP, 2005. 